\title{
Antioxidant activities of phenolic rich fractions (PRFs) obtained from black mahlab (Monechma ciliatum) and white mahlab (Prunus mahaleb) seedcakes
}

\begin{abstract}
The antioxidant activities of phenolic rich fractions (PRFs) from crude methanolic extract (CME), and its fractions using ethyl acetate (EAF), hexane (HF) and water (WF) of black mahlab (Monechma ciliatum) and white mahlab (Prunus mahaleb) seedcakes were investigated. The total phenolic compounds were found to be higher in white mahlab than black mahlab seedcakes. The antioxidant activity determined by the DPPH method revealed that black mahlab PRFs had the highest antioxidant activity, compared to white mahlab fractions. The presence of antioxidants in the two mahlab PRFs reduced the oxidation of $\beta$ carotene by hydroperoxides from these extracts/fractions. The effect of the two mahlab PRFs on the oxidative stability of corn oil at $70{ }^{\circ} \mathrm{C}$ was tested in the dark and compared with butylated hydroxyanisole (BHA). The CME performed better antioxidant activity in inhibiting the formation of both primary and secondary oxidation products. The qualitative and quantitative characterisation of phenolic compounds was carried out by HPLC/DAD.
\end{abstract}

Keyword: $\beta$-Carotene-linoleic acid assay; 1,1-Diphenyl-2-picrylhydrazyl (DPPH); Antioxidant activity; Monechma ciliatum; Phenolic rich fractions; Prunus mahaleb 